\title{
Scaling of the appendicular skeleton of the giraffe (Giraffa camelopardalis)
}

\author{
Sybrand van Sittert, ${ }^{*}$ John Skinner, ${ }^{1+}$ and Graham Mitchell ${ }^{1,2}$ \\ ${ }^{1}$ Centre for Veterinary Wildlife Studies, Department of Production Animal Studies, University of \\ Pretoria, Onderstepoort, South Africa \\ ${ }^{2}$ Department of Zoology and Physiology, University of Wyoming, Laramie, Wyoming, USA \\ † Deceased 28 August 2011.
}

*Correspondence to: Sybrand van Sittert (attn: Ms Marie Watson), Centre for Veterinary Wildlife Studies, Department of Production Animal Studies, Faculty of Veterinary Science, University of Pretoria, Onderstepoort, 0110, South Africa. E-mail: sybrandvs@gmail.com

\begin{abstract}
Giraffes have remarkably long and slender limb bones, but it is unknown how they grow with regard to body mass, sex and neck length. In this study we measured the length, medio-lateral diameter (ML), cranio-caudal diameter $(\mathrm{CC})$ and circumference of the humerus, radius, metacarpus, femur, tibia and metatarsus in 10 fetuses, 21 females and 23 males of known body masses. Allometric exponents were determined and compared. We found the average bone length increased from $340 \pm 50 \mathrm{~mm}$ at birth to $700 \pm 120 \mathrm{~mm}$ at maturity, while average diameters increased from $30 \pm 3 \mathrm{~mm}$ to $70 \pm 11 \mathrm{~mm}$. Fetal bones increased with positive allometry in length (relative to body mass) and in diameter (relative to body mass and length). In postnatal giraffes bone lengths and diameters increased iso- or negatively allometric relative to increases in body mass, except for the humerus $\mathrm{CC}$ diameter which increased with positive allometry. Humerus circumference also increased with positive allometry, that of the radius and tibia isometrically and the femur and metapodials with negative allometry.
\end{abstract}


Relative to increases in bone length, both the humerus and femur widened with positive allometry. In the distal limb bones ML diameters increased isometrically (radius, metacarpus) or positively allometric (tibia, metatarsus) while the corresponding CC widths increased with negative allometry and isometrically respectively. Except for the humerus and femur, exponents were not significantly different between corresponding front and hind limb segments.

We concluded that the patterns of bone growth in males and females are identical. In fetuses the growth of the appendicular skeleton is faster than it is after birth which is a pattern opposite to that reported for the neck. Allometric exponents seemed unremarkable compared to the few species described previously, and pointed to the importance of neck elongation rather than leg elongation during evolution. Nevertheless, the front limb bones and especially the humerus may show adaptation to behaviors such as drinking posture.

Keywords: giraffe, allometry, long bones, ontogeny, appendicular skeleton

\section{Introduction}

The scaling of long bones is not fully understood. As animals become bigger, more robust bones are expected in order to keep bone strains along the bone diaphyses similar (Galilei, 1914). McMahon $(1973,1975)$ postulated that bones increased in size in a way not to retain similar bone strain levels across body masses but rather to prevent buckling, which became known as the elastic similarity model. If this model is correct, then bone length $(L)$ should be proportional to $(\propto)$ diameter $(D)$ to the power 
$0.67, \mathrm{~L} \propto$ body mass $(\mathrm{Mb})^{0.25}, \mathrm{D} \propto \mathrm{Mb}^{0.38}$ and cross sectional area $\propto \mathrm{Mb}^{0.75}$. McMahon confirmed his idea by measuring the long bone diameter and length of 72 species of artiodactyls, including giraffes. However, when Alexander et al. (1979) retested the elastic similarity model on a broader range of species (not including giraffes) they found, perplexingly, that bones tend to scale closer to isometry (or geometric similarity) across taxa, and that elastic similarity applied mainly to bovids. So far, no single model has emerged that adequately describes regular distortions in bone shape across different adult body sizes (Biewener, 1983; Economos, 1983; Selker and Carter, 1989; Currey, 2002; Kokshenev, 2003; Garcia and da Silva, 2006).

Most of the research into limb bone allometry has been on interspecific samples, with few devoted to ontogenetic scaling. As the relationship between interspecific and ontogenetic bone allometry has not been elucidated yet, it is also uncommon to apply interspecific models, such as elastic similarity, to ontogenetic data (e.g. Miller et al., 2008). Accordingly, limb bone ontogenies have usually only been interpreted in terms of deviations from geometric similarity. A further limitation regarding studies on limb bone ontogeny is that smaller mammals are very much overrepresented, with artiodactyls and other large animals receiving little attention.

Initially it seemed, save for a few exceptions, that increasingly gracile bones throughout growth was the prevailing pattern in mammals (Carrier, 1983; Heinrich et al., 1999; Lammers and German, 2002; Main and Biewener, 2004; Miller et al., 2008). However, when Kilbourne and Makovicky (2012) investigated a larger sample base including larger animals, they showed that increasingly gracile bones were a feature of 
animals below $20 \mathrm{~kg}$ adult body mass, while increasingly robust bones were mainly confined to the artiodactyla. Interestingly the okapi (Okapia johnstoni), the only giraffid to be included in their study sample, was an exception as its bones became increasingly gracile throughout ontogeny.

Giraffes (Giraffa camelopardalis) are the tallest extant animals. Tallness has been accomplished through the evolution of a compact thorax and elongated neck and legs. We have previously described the ontogenetic allometry of the vertebral column (van Sittert et al., 2010) and found, briefly, that neck elongation occurs at the fastest relative rate after birth, that the $\mathrm{C} 2-\mathrm{C} 7$ vertebrae elongate at equal rates and that neck elongation is accompanied by enlargement of the spines of the thoracic vertebrae to provide attachment of the nuchal ligament. We have also reported on how limb bones develop strength to support the large body mass. The density of giraffe limb bones is approximately $50 \%$ more than it is in other bones, their limb bones are straighter than in other artiodactyls, the wall thickness is significantly thicker than in equivalent mass artiodactyls and the metapodials have a unique columned structure (Biewener, 1983; van Schalkwyk et al., 2004). The ontogeny of giraffe limb bones is however still unknown.

Giraffe limb bones are of particular interest as they are exceptionally gracile and do not seem to conform to mammalian scaling patterns. In 1917 D'Arcy Thompson pointed out that giraffe metatarsals are relatively and absolutely longer than they are in the far less heavy ox, confounding the general observation that heavier animals have relatively stockier and shorter limbs in order to support body mass. Similarly, 
McMahon (1975) also found it difficult to reconcile giraffe distal limb bones with his elastic similarity model. We report here the results of an ontogenetic study of the appendicular skeleton of giraffes ranging in body mass from a fetus weighing $18 \mathrm{~kg}$ to a mature $(>1400 \mathrm{~kg}$ ) animal. We related giraffe ontogeny to known ontogenetic trends in other species (Kilbourne and Makovicky, 2012), as well as to known growth data on its long neck (van Sittert et al., 2010), in order to test if increasingly robust bones during ontogeny will also apply to large animals with an extreme shape. As with other ontogenetic allometric studies we evaluated limb bone growth in terms of deviations from geometric similarity. In addition, we also compared giraffe scaling patterns to the theory of elastic similarity to see if protection against buckling may have an influence in the ontogeny of long slender limbs.

As giraffe tallness is brought about by elongation of neck and limbs, we expected similar scaling patterns with regard to length in both these body regions. Therefore, we anticipated that giraffe leg elongation exponents will be higher postnatally than in the fetus and that there will be a lack of sexual dimorphism in lengthening, as sexual selection did not seem to play a major role in the evolution of tallness in this animal (Mitchell et al., 2009; van Sittert et al., 2010). Because of the relative slenderness and length of the giraffe limb bones (and similar to the okapi data presented by Kilbourne and Makovicky, 2012), we expected limb bones to become increasingly gracile throughout ontogeny. This would also mean non-compliance with the principle of elastic similarity, especially in the distal bones. In addition we hypothesized that the greatest bone lengthening rates would occur in the metapodial bones given the great 
interspecific variation in this region (Thompson, 1917; McMahon, 1975; Miller et al., 2008).

\section{Materials and methods}

\section{Sampling}

A cross-sectional sample of giraffe specimens was obtained from animals culled as part of the routine management of a conservancy in south eastern Zimbabwe $\left(21^{\circ} 42^{\prime} \mathrm{S}\right.$, $29^{\circ} 54^{\prime}$ E). Samples were collected from April 2007 until December 2010 from 10 fetuses, 21 females, and 23 males. The study was approved by the research and ethics committee of the University of Pretoria (protocol ref V043.08).

\section{Body mass}

The body mass for each animal was determined by piecemeal weighing using a Salter suspended spring balance with a capacity of $200 \mathrm{~kg}$. The whole carcass, including gastrointestinal and reproductive contents, was measured in this way. Following HallMartin (1975), 4\% was added to measured body mass as a reasonable approximation for the mass lost by evaporation, blood loss, and the loss of small pieces of tissue during the slaughtering process. The body masses of fetuses were, however, measured in toto and no corrections were made to their measured body masses.

\section{Bone preparation}

Foreleg bones prepared for study were the humerus, radius, fused metacarpal bones 3 and 4 (= metacarpus), femur, tibia, and fused metatarsal bones 3 and 4 (= metatarsus). 
After the carcasses were weighed, the muscles and ligaments were removed by dissection and boiling in mature giraffes. In the case of fetuses or immature animals the bones were not boiled but only dissected so as to avoid dislodgement of the epiphyses.

\section{Bone measurements}

On each bone, length was measured in a straight line parallel to the long axis of the bone between the borders of the most proximal to most caudal part, which included processes, tubercles, condyles or heads of bones. The radial and tibial lengths did not include the ulna or fibula. Cranio-caudal and medio-lateral diameter as well as circumference were measured at the bone midshaft, perpendicular to the long axis of the bone. In addition, after sectioning bones at their midshaft, cross sectional cortical thicknesses were also measured using a vernier caliper at cranial, caudal, lateral and medial positions (Figure 1). The radial and tibial diameters and circumferences included the ulna and fibula respectively due to the very intimate association of these bones with each other in the giraffe. For the metapodial bones, the cranio-caudal diameter included the caudal "pillars" as described by van Schalkwyk et al. (2004). The cross sectional area (CSA) of each bone at midshaft was estimated by assuming its shape approximates an ellipse and using the following formula for the area of an ellipse: area $=\pi * r 1 * r 2$, where $r 1$ and $r 2$ constitute the cranio-caudal and mediolateral radii. 


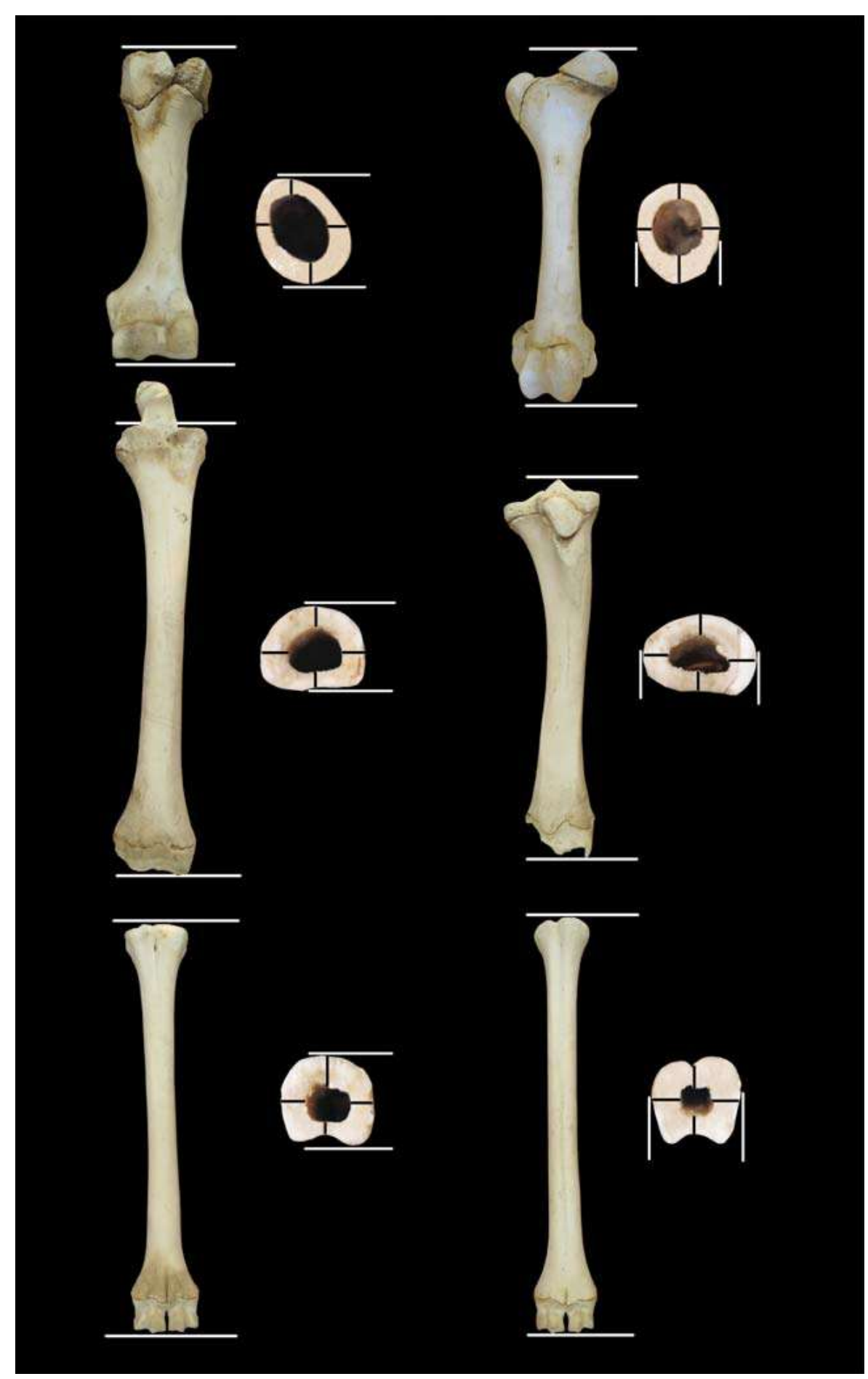

Fig. 1. Long bones of the giraffe. The bones are presented in cranial view and in cross section (not to scale). The cross-sectional view is positioned so that the cranial side faces to the top the page. The white lines illustrate length measurements, as well as the CC and ML measurements (indicated on the front and hind limb cross sections, respectively). Black lines denote cortical thickness measurements.

Anatomical landmarks for the length measurements were as follows: Humerus, Tuberculum majus to distal surface of Capitulum humeri; Radius, Caput radii to Processus styloideus lateralis; Metapodials, Articular surface of head to articular surface of base; Femur, Proximal Caput ossis femoris to distal surface of Condylus lateralis; Tibia, Eminentia intercondylaris to Malleolus medialis. 


\section{Scaling model}

Growth data were plotted on bivariate charts. One of the methods available to assess growth patterns is the study of relative bone growth, or allometry. We found the allometric equation the most convenient and easily manageable method to describe growth $\left(y=m x^{b}\right.$, where $y$ is the variable described, $m$ the allometric constant and $b$ relative growth rate, referred to as the allometric exponent or slope; Huxley, 1932). When the allometric equation is log transformed it forms a linear relationship between $y$ and $x: \ln (y)=\ln (m)+b^{*} \ln (x)$, which were used to estimate $m$ and $b$ using standardized major axis (model II) regression (Warton et al., 2006). Two hypotheses were tested regarding the allometric exponent: firstly whether or not two data groups have the same exponent (e.g. fetal vs. postnatal exponents), and secondly if an exponent equaled a specific value (e.g. isometry $=1)$. Table 1 shows the values for exponents complying with geometric or elastic similarity, as well as for increasingly gracile or robust bones.

\section{Statistics}

Allometric analysis were performed according to the recommendations of Warton et al (2006) using the SMATR executable software program (Falster et al., 2006), available at http://www.bio.mq.edu.au/ecology/SMATR/. Briefly, to test if two data groups have the same allometric exponent, a likelihood ratio test for a common slope was used and compared to a chi squared distribution. Secondly, to test whether or not a slope equals some hypothesized value of $b$, a test for correlation between residual and fitted axis scores were conducted, using the hypothesized value as slope. 
Table 1 Summary of the various allometric patterns. For each scenario, the expected scaling exponent (b) for the equation $\mathrm{y}=m \mathrm{x}^{\mathrm{b}}$ is given.

\begin{tabular}{|c|c|c|c|c|c|}
\hline $\begin{array}{l}\text { Type of } \\
\text { allometry }\end{array}$ & $\begin{array}{l}\text { Length vs } \\
\text { Body mass }\end{array}$ & $\begin{array}{l}\text { Diameter and } \\
\text { circumference } \\
\text { vs Body mass }\end{array}$ & $\begin{array}{l}\text { Cross sectional } \\
\text { area vs Body } \\
\text { mass }\end{array}$ & $\begin{array}{l}\text { Diameter and } \\
\text { circumference } \\
\text { vs Bone length }\end{array}$ & $\begin{array}{l}\text { Cross sectional } \\
\text { area vs Bone } \\
\text { length }\end{array}$ \\
\hline $\begin{array}{l}\text { Isometric/ } \\
\text { geometric } \\
\text { similarity }\end{array}$ & 0.333 & 0.333 & 0.666 & 1.00 & 2.00 \\
\hline $\begin{array}{l}\text { Increasingly } \\
\text { gracile bones }\end{array}$ & & $<0.333$ & $<0.666$ & $<1.00$ & $<2.00$ \\
\hline $\begin{array}{l}\text { Increasingly } \\
\text { robust bones }\end{array}$ & $<0.333$ & $>0.333$ & $>0.666$ & $>1.00$ & $>2.00$ \\
\hline $\begin{array}{l}\text { Elastic } \\
\text { similarity }\end{array}$ & 0.25 & 0.375 & 0.75 & 1.5 & 2.25 \\
\hline
\end{tabular}

Wherever a group of two or more slopes were simultaneously considered to be significantly different from a hypothesized value, the significance level for each test in the group was adjusted according to the sequential Bonferroni method (Rice, 1989). In this way the group-wise significance level $(\alpha)$ was kept at 0.05 . The number of tests $(k)$ in each group was determined by the hypothesis to be tested. For example: 'giraffe long bones grow in length to body mass according to geometric similarity postnatally' will have 6 bone's exponents to test simultaneously, and each sequential test (i) will have to be $p_{i} \leq \alpha /(1+k-i)$, in order to be considered significantly different from geometric similarity. 


\section{Results}

Sample description

Body masses of the animals in the study $(n=47)$ ranged from $18 \mathrm{~kg}$ to $1409 \mathrm{~kg}$ in males and from $21 \mathrm{~kg}$ to $1028 \mathrm{~kg}$ in females. Fetal (n=10) weights ranged from $18 \mathrm{~kg}$ to $77 \mathrm{~kg}$ (a full term fetus is estimated at ca. 100kg (Skinner and Hall-Martin, 1975). The body mass of postnatal animals ranged from $147 \mathrm{~kg}$ to $1028 \mathrm{~kg}$ in females $(n=20)$ and from $184 \mathrm{~kg}$ to $1409 \mathrm{~kg}$ in males ( $\mathrm{n}=17)$. The size range within this study thus differed by a factor of 4 from youngest to oldest fetus, 78 from fetus to adult and by a factor of 14 from neonate to adult. Although the total number of animals sampled was 47 , all dimensions could not be measured in each case, and the number of animals sampled for each dimension is shown in the tables or figures where relevant. As the postnatal dataset was much larger than the fetal dataset it had more power for detecting significant differences between allometric exponents. Therefore, fetal data were not analyzed to the extent of postnatal data.

\section{Sexual dimorphism}

We could not detect significant sexual dimorphism for any of the growth patterns of

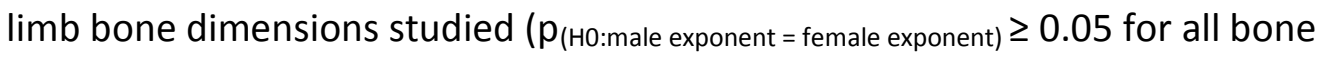
dimension vs. body mass slopes as well as for all bone cross sectional dimension vs. bone length slopes). Data from both genders were therefore pooled. 


\section{Growth patterns}

Growth in length with regard to body mass

The exponents, correlation coefficients and significance values for bone lengthening in fetuses and postnatal giraffes are summarized in Table 2 and the growth curves for postnatal giraffes are shown in Fig 2.

Table 2. Summary of the bone length vs. body mass slopes. Data were subdivided into fetal and postnatal data. The last two columns indicate the probability of the exponent $(b)$ being geometrically similar $(0.333)$ or elastically similar (0.25). The significance level was adjusted according to the sequential Bonferroni technique (Rice, 1989). Postnatal bone growth patterns are highlighted with a key: — geometric similarity, $\square$ elastic similarity, $\Delta$ positive allometry, $\boldsymbol{\nabla}$ negative allometry. In cases where growth could not be distinguished from either geometric similarity or elastic similarity, or where allometries were both negative and elastically similar, two keys are shown [were indicated]. $\mathrm{n}=$ number of animals sampled, $\mathrm{Cl}=$ confidence interval, $\mathrm{F}=$ fetus, $\mathrm{PN}=$ postnatal animal.

\begin{tabular}{|c|c|c|c|c|c|c|c|c|c|}
\hline & Group & $n$ & $r^{2}$ & Exponent & $95 \% \mathrm{Cl}$ & Intercept & $\begin{array}{c}\text { P (HO: } \\
\text { fetal- = } \\
\text { postnatal } \\
\text { slope) }\end{array}$ & $\begin{array}{c}\mathrm{P}(\mathrm{HO}: \mathrm{b}=0.333 \text { ) } \\
\text { (geometric) }\end{array}$ & $\begin{array}{c}\mathrm{P}(\mathrm{HO}: \mathrm{b}=0.25) \\
\quad \text { (elastic) }\end{array}$ \\
\hline Front leg total & $\mathrm{F}$ & 7 & 0.98 & 0.376 & 0.324 to 0.435 & 174.2 & & 0.09 & $<0.01$ \\
\hline$-/ \square$ & PN & 14 & 0.93 & 0.295 & 0.249 to 0.350 & 225.9 & 0.02 & 0.15 & 0.05 \\
\hline Hind leg total & $\mathrm{F}$ & 7 & 0.99 & 0.351 & 0.313 to 0.395 & 203.6 & & 0.29 & $<0.01$ \\
\hline$\nabla / \square$ & PN & 16 & 0.95 & 0.276 & 0.243 to 0.312 & 276.7 & $<0.01$ & 0.01 & 0.11 \\
\hline Humerus & $\mathrm{F}$ & 7 & 0.98 & 0.373 & 0.313 to 0.445 & 48.7 & & 0.16 & $<0.01$ \\
\hline- & PN & 16 & 0.96 & 0.304 & 0.269 to 0.343 & 63.2 & 0.06 & 0.13 & $<0.01$ \\
\hline Radius & $\mathrm{F}$ & 7 & 0.99 & 0.340 & 0.302 to 0.383 & 75.7 & & 0.66 & $<0.01$ \\
\hline- & PN & 15 & 0.97 & 0.346 & 0.310 to 0.386 & 70.1 & 0.80 & 0.47 & $<0.01$ \\
\hline Metacarpus & $\mathrm{F}$ & 10 & 0.97 & 0.390 & 0.337 to 0.451 & 73.9 & & 0.04 & $<0.01$ \\
\hline- & PN & 36 & 0.91 & 0.300 & 0.271 to 0.333 & 89.5 & $<0.01$ & 0.05 & $<0.01$ \\
\hline Femur & $\mathrm{F}$ & 7 & 0.98 & 0.409 & 0.342 to 0.490 & 46.3 & & 0.03 & $<0.01$ \\
\hline$\nabla / \square$ & PN & 16 & 0.96 & 0.249 & 0.221 to 0.281 & 94.9 & $<0.01$ & $<0.01$ & 0.96 \\
\hline Tibia & $\mathrm{F}$ & 7 & 0.98 & 0.369 & 0.314 to 0.434 & 57.9 & & 0.16 & $<0.01$ \\
\hline- & PN & 16 & 0.96 & 0.302 & 0.269 to 0.340 & 77.9 & 0.04 & 0.1 & $<0.01$ \\
\hline Metatarsus & $\mathrm{F}$ & 10 & 0.95 & 0.315 & 0.265 to 0.375 & 96.5 & & 0.49 & 0.02 \\
\hline - & PN & 37 & 0.9 & 0.300 & 0.270 to 0.334 & 88.6 & 0.62 & 0.06 & $<0.01$ \\
\hline
\end{tabular}



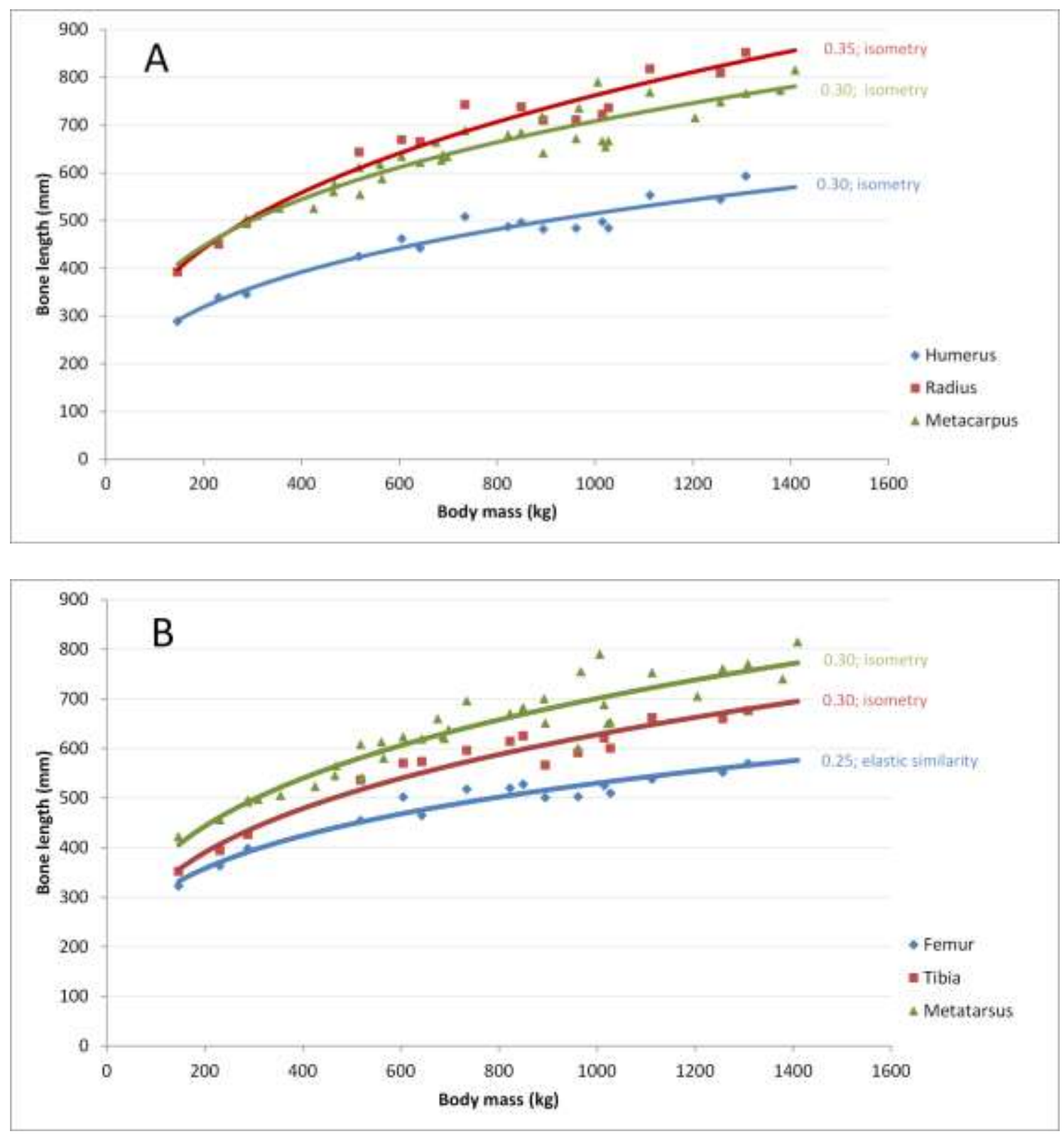

Fig. 2. Growth of the (A) front limb and (B) hind limb bone length relative to body mass in postnatal animals. Note that curves with the same exponent will differ in presentation because of different allometric coefficients. All exponents except the femur were significantly greater than elastic similarity, but not different from geometric similarity/isometry. The allometric exponent and its classification are indicated next to each curve.

Fetal limbs grew relatively faster than postnatal limbs: Exponents of total leg length (constituent bones combined) vs. body mass were significantly greater in the fetus

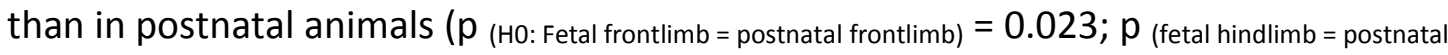
hindlimb $)=0.006)$. Considering individual bones, the metacarpus $\left(\mathrm{p}_{(\mathrm{HO}: \mathrm{fetal}=\text { postnatal exponent })}=\right.$ 
0.004 ) and femur ( $p_{\text {(HO:fetal=postnatal exponent })}=0.001$ ) grew faster in the fetus than postnatally. On the other hand there were no significant pre- and postnatal differences in the humerus $\left(p_{\text {HO:fetal=postnatal exponent }}=0.06\right)$, radius $\left(p_{\text {HO: fetal=postnatal exponent }}=0.80\right)$, tibia $\left(p_{(\text {Ho:fetal=postnatal exponent })}=0.03\right.$; sequential Bonferonni adjusted significance level) and metatarsus $\left(p_{(\text {fetal=postnatal exponent })}=0.62\right)$. The lack of significant differences could mean that the bones grew at a similar rate pre- and postnatally (probably radius and metatarsus) or that confidence intervals were too wide to detect a difference (probably humerus and tibia).

In the postnatal animal, total front- and hind limb growth could be summarized with a common negatively allometric exponent of 0.28 (95\% confidence interval $=0.26-0.31$; $\left.\mathrm{p}_{\text {(HO:front limb exponent=hind limb exponent) }}=0.50\right)$. This common slope is neither truly elastically $\left(p_{(H O: b=0.25)}=0.02\right)$ nor geometrically similar $\left(p_{(H O: b=0.33)}=0.002\right)$. The constituent front and hind limb zeugopodial (radius and tibia) and metapodial (metacarpus and metatarsus) limb bones could be summarized with common slopes ( 0.33 and 0.30 respectively), but the humerus and femur had significantly different slopes ( $p_{\text {(HO:humerus }}$ slope $=$ femur slope $)=0.015$ )

The individual fetal exponents were significantly greater than the elastic similarity exponent in all cases $\left.\left(p_{(H O:} b=0.25\right) \leq 0.002\right)$. Similarly, all the individual postnatal bone exponents except the femur were significantly greater than elastic similarity $\left(p_{(\mathrm{HO}: \mathrm{b}}=\right.$ $0.25)=\leq 0.004$ ), but not significantly different to geometric similarity. Thus, none of the individual postnatal limb bones grew faster in length relative to increases in body mass. 
Table 3 Bone lengths at different life stages, using allometric equations described in this study. The $100 \mathrm{~kg}$ predictions displayed here are the average of fetal and post natal equations for $100 \mathrm{~kg}$. Predictions in $\mathrm{mm}$, with the percentage the bone contributes to the respective limb noted below the absolute value.

\begin{tabular}{|l|l|l|l|l|l|}
\hline & $\mathbf{5 0 k g}$ & $\mathbf{1 0 0 k g}$ & $\mathbf{5 0 0 k g}$ & $\mathbf{1 0 0 0 k g}$ & $\mathbf{1 3 0 0 k g}$ \\
\hline humerus & 210 & 264 & 418 & 516 & 559 \\
& $25 \%$ & $26 \%$ & $26 \%$ & $26 \%$ & $26 \%$ \\
\hline radius & 286 & 354 & 602 & 765 & 838 \\
\hline metacarpus & $34 \%$ & $35 \%$ & $38 \%$ & $38 \%$ & $39 \%$ \\
\hline Total front limb length & 836 & 401 & 577 & 711 & 769 \\
\hline femur & 340 & $39 \%$ & $36 \%$ & $36 \%$ & $36 \%$ \\
\hline tibia & 229 & 302 & 446 & 530 & 566 \\
\hline Total hind limb length & 805 & $30 \%$ & $29 \%$ & $28 \%$ & $28 \%$ \\
\hline & $28 \%$ & 999 & 1527 & 1861 & 2006 \\
\hline & $30 \%$ & $32 \%$ & $33 \%$ & $34 \%$ & $34 \%$ \\
\hline
\end{tabular}

Table 3 shows the absolute lengths and proportions of the bones in fetal $(50 \mathrm{~kg})$ and postnatal giraffes (100 to $1300 \mathrm{~kg}$ ). The sum of the lengths of the front limb bones was longer than the total length of the hind limb bones throughout ontogeny (from about $19 \mathrm{~mm}$ longer in a neonate to about $160 \mathrm{~mm}$ longer in an adult $1300 \mathrm{~kg}$ giraffe). The humerus and femur were always the shortest of the bones: In the front limb the proportional contribution of the humerus to the total was relatively constant at $25.7 \pm 0.5 \%$, while the femur's decreased from $30.2 \%$ to $28.2 \%$ of the hind limb. The 
proportion of total length formed by the radius and tibia increased from $34.7 \%$ and $31.5 \%$ to $38.7 \%$ and $33.8 \%$ of limb length respectively. Conversely, the proportion of leg length contributed by the metacarpus decreased from $39.4 \%$ to ca. $35.5 \%$, while that of the metatarsus remained $c a .38 \%$. In the forelimb the radius started shorter and ended longer than the metacarpus, overtaking the metacarpus in the first year of life while in the hind limb the tibia was always shorter than the metatarsus (a oneyear-old giraffe weighs between 260 and $300 \mathrm{~kg}$; G Mitchell, unpublished data). As final metapodial lengths are similar the final difference of $160 \mathrm{~mm}$ between fore- and hind limb total bone length is almost completely a consequence of the difference in lengths of the tibia and radius (159 $\mathrm{mm}$ ).

\section{Cross sectional properties}

Increase in diameter and circumference with body mass as the covariate

Table 4, Table 5 and Figure 3 summarizes changes in diameter as body mass increases. A one way ANOVA was conducted to test for differences in the mean diameter vs. body mass slopes of fetal cranio-caudal and medio-lateral as well as postnatal craniocaudal and medio-lateral dimensions. Slopes were significantly different amongst the four groups $\left(F_{(3,20)}=23.76, p<0.001\right)$. Post hoc tests indicated that mean fetal diameter exponents were significantly higher $(p<0.01)$ than postnatal animals (mean cranio-caudal $(\mathrm{CC})$ slope fetus $=0.46 \pm 0.04$, mean medio-lateral $(\mathrm{ML})$ slope fetus $=0.45$ \pm 0.03 , mean CC slope postnatal $=0.32 \pm 0.05$, mean $\mathrm{ML}$ slope postnatal $=0.35 \pm 0.03$ ) The $95 \%$ confidence intervals for mean fetal diameters were higher than both isometry 
Table 4 Allometric equations describing growth in diameter (cranio-caudal and medio-lateral) and circumference with regard to body mass. The last two columns indicate the probability of the exponent (b) being geometrically similar (0.333) or elastically similar (0.375). The significance level for each test was adjusted according to the sequential Bonferroni technique (Rice, 1989). Postnatal bone growth patterns are highlighted with a key: - geometric similarity, $\square$ elastic similarity, $\Delta$ positive allometry, $\nabla$ negative allometry. In cases where growth could not be distinguished from either geometric similarity or elastic similarity, or where allometries were both positive and elastically similar, two keys are shown [were indicated]. $n=$ number of animals sampled, $\mathrm{Cl}=$ confidence interval, $\mathrm{F}=$ fetus, $\mathrm{PN}=$ postnatal animal, $\mathrm{CC}=$ cranio-caudal diameter, $\mathrm{ML}=$ medio-lateral diameter, circ = circumference, $\mathbf{H}=$ Humerus, $\mathrm{R}=$ Radius, $\mathrm{Mc}=$ Metacarpus, $\mathrm{F}=$ Femur, $\mathrm{T}=$ Tibia, $\mathrm{Mt}=$ Metatarsus.

\begin{tabular}{|c|c|c|c|c|c|c|c|c|}
\hline & $\begin{array}{l}\text { Age } \\
\text { group }\end{array}$ & $\mathbf{n}$ & r2 & Slope & $95 \% \mathrm{Cl}$ & Intercept & $\begin{array}{c}\mathrm{p}(\mathrm{HO}: \mathrm{b}=0.333) \\
\text { (geometric) }\end{array}$ & $\begin{array}{c}\mathrm{P}(\mathrm{HO} 0: \mathrm{b}=0.375) \\
\text { (elastic) }\end{array}$ \\
\hline H CC & $\mathrm{F}$ & 7 & 0.89 & 0.525 & 0.364 to 0.758 & 3.78 & 0.02 & 0.07 \\
\hline$\Delta / \square$ & PN & 13 & 0.96 & 0.423 & 0.373 to 0.480 & 4.39 & $<0.01$ & 0.06 \\
\hline H ML & $\mathrm{F}$ & 7 & 0.96 & 0.442 & 0.350 to 0.557 & 5.05 & 0.03 & 0.13 \\
\hline -/口 & PN & 13 & 0.92 & 0.379 & 0.315 to 0.456 & 5.21 & 0.16 & 0.91 \\
\hline H circ & $\mathrm{F}$ & 7 & 0.99 & 0.414 & 0.364 to 0.471 & 18.2 & 0.01 & 0.10 \\
\hline$\Delta / \square$ & PN & 16 & 0.97 & 0.386 & 0.348 to 0.427 & 16.3 & 0.01 & 0.56 \\
\hline R CC & $\mathrm{F}$ & 7 & 0.99 & 0.421 & 0.374 to 0.473 & 4.60 & $<0.01$ & 0.05 \\
\hline 一 & PN & 13 & 0.97 & 0.309 & 0.274 to 0.348 & 6.49 & 0.19 & $<0.01$ \\
\hline R ML & $\mathrm{F}$ & 7 & 0.99 & 0.460 & 0.381 to 0.556 & 4.48 & $<0.01$ & 0.04 \\
\hline$-/ \square$ & PN & 13 & 0.98 & 0.371 & 0.337 to 0.407 & 5.37 & 0.03 & 0.78 \\
\hline $\mathbf{R}$ circ & $\mathrm{F}$ & 7 & 0.97 & 0.389 & 0.319 to 0.474 & 18.8 & 0.10 & 0.67 \\
\hline 一 & PN & 16 & 0.98 & 0.337 & 0.308 to 0.369 & 20.1 & 0.80 & 0.02 \\
\hline $\mathrm{Mc} \mathrm{CC}$ & $\mathrm{F}$ & 7 & 0.97 & 0.479 & 0.333 to 0.689 & 3.56 & 0.01 & 0.15 \\
\hline$\nabla$ & PN & 24 & 0.95 & 0.286 & 0.258 to 0.318 & 7.03 & 0.01 & $<0.01$ \\
\hline Mc ML & $\mathrm{F}$ & 7 & 0.90 & 0.502 & 0.345 to 0.730 & 3.60 & 0.05 & 0.10 \\
\hline -/口 & PN & 24 & 0.96 & 0.331 & 0.302 to 0.363 & 5.70 & 0.90 & 0.01 \\
\hline Mc circ & $\mathrm{F}$ & 7 & 0.99 & 0.413 & 0.371 to 0.460 & 16.5 & $<0.01$ & 0.07 \\
\hline $\boldsymbol{\nabla}$ & PN & 31 & 0.95 & 0.301 & 0.277 to 0.327 & 22.8 & 0.02 & $<0.01$ \\
\hline $\mathrm{FCC}$ & $\mathrm{F}$ & 7 & 0.90 & 0.453 & 0.315 to 0.652 & 5.02 & 0.08 & 0.25 \\
\hline 一 & PN & 13 & 0.97 & 0.311 & 0.280 to 0.346 & 7.85 & 0.19 & $<0.01$ \\
\hline F ML & $\mathrm{F}$ & 7 & 0.86 & 0.484 & 0.317 to 0.739 & 4.22 & 0.07 & 0.19 \\
\hline 一 & PN & 13 & 0.98 & 0.306 & 0.280 to 0.335 & 6.89 & 0.06 & $<0.01$ \\
\hline F circ & $\mathrm{F}$ & 7 & 0.94 & 0.371 & 0.281 to 0.490 & 21.4 & 0.37 & 0.92 \\
\hline $\boldsymbol{\nabla}$ & PN & 16 & 0.97 & 0.293 & 0.266 to 0.324 & 25.7 & 0.02 & $<0.01$ \\
\hline TCC & $\mathrm{F}$ & 7 & 0.90 & 0.464 & 0.324 to 0.665 & 3.86 & 0.07 & 0.19 \\
\hline 一 & PN & 13 & 0.91 & 0.296 & 0.244 to 0.359 & 6.82 & 0.21 & 0.02 \\
\hline $\mathrm{T} \mathrm{ML}$ & $\mathrm{F}$ & 7 & 0.77 & 0.429 & 0.254 to 0.724 & 5.53 & 0.28 & 0.56 \\
\hline$-/ \square$ & PN & 13 & 0.98 & 0.335 & 0.301 to 0.372 & 7.11 & 0.93 & 0.04 \\
\hline T circ & $\mathrm{F}$ & 7 & 0.94 & 0.338 & 0.253 to 0.451 & 23.9 & 0.91 & 0.40 \\
\hline 一 & PN & 16 & 0.98 & 0.308 & 0.282 to 0.337 & 24.0 & 0.08 & $<0.01$ \\
\hline Mt CC & $\mathrm{F}$ & 7 & 0.97 & 0.454 & 0.368 to 0.561 & 3.74 & 0.01 & 0.07 \\
\hline - & PN & 24 & 0.94 & 0.296 & 0.266 to 0.330 & 6.69 & 0.03 & $<0.01$ \\
\hline Mt ML & $\mathrm{F}$ & 7 & 0.94 & 0.435 & 0.331 to 0.572 & 4.35 & 0.05 & 0.23 \\
\hline -/口 & PN & 24 & 0.93 & 0.350 & 0.312 to 0.392 & 4.71 & 0.38 & 0.22 \\
\hline
\end{tabular}




\begin{tabular}{|c|c|c|c|c|c|c|c|c|}
\hline Mt circ & F & 7 & 0.93 & 0.384 & 0.285 to 0.518 & 2.88 & 0.28 & 0.84 \\
\hline $\boldsymbol{\nabla}$ & PN & 31 & 0.93 & 0.299 & 0.270 to 0.330 & 3.11 & 0.04 & $<0.01$ \\
\hline
\end{tabular}

Table 5 Mean bone diameters (average of cranio-caudal and medio-lateral diameters) and circumferences at different life stages of the giraffe. The $100 \mathrm{~kg}$ predictions are the average of fetal and post natal equations for 100 kg. Predictions in $\mathrm{mm}$.

\begin{tabular}{|c|c|c|c|c|c|}
\hline Body mass & $50 \mathrm{~kg}$ & $100 \mathrm{~kg}$ & $500 \mathrm{~kg}$ & $1000 \mathrm{~kg}$ & $1300 \mathrm{~kg}$ \\
\hline \multicolumn{6}{|c|}{ Average diameter } \\
\hline Humerus & 30 & 35 & 59 & 77 & 85 \\
\hline Radius & 26 & 31 & 50 & 63 & 69 \\
\hline Metacarpus & 24 & 30 & 44 & 54 & 58 \\
\hline Femur & 28 & 35 & 52 & 64 & 69 \\
\hline Tibia & 26 & 33 & 50 & 62 & 67 \\
\hline Metarsus & 23 & 28 & 42 & 52 & 56 \\
\hline \multicolumn{6}{|c|}{ Average circumference } \\
\hline Humerus & 92 & 109 & 179 & 234 & 259 \\
\hline Radius & 86 & 103 & 163 & 205 & 224 \\
\hline Metacarpus & 83 & 101 & 148 & 182 & 197 \\
\hline Femur & 91 & 109 & 159 & 195 & 211 \\
\hline Tibia & 90 & 106 & 163 & 202 & 219 \\
\hline Metarsus & 80 & 97 & 144 & 177 & 191 \\
\hline
\end{tabular}

(viz., 0.33) and elastic similarity (viz., 0.38), whereas the confidence intervals for mean postnatal growth were not different from isometry. 

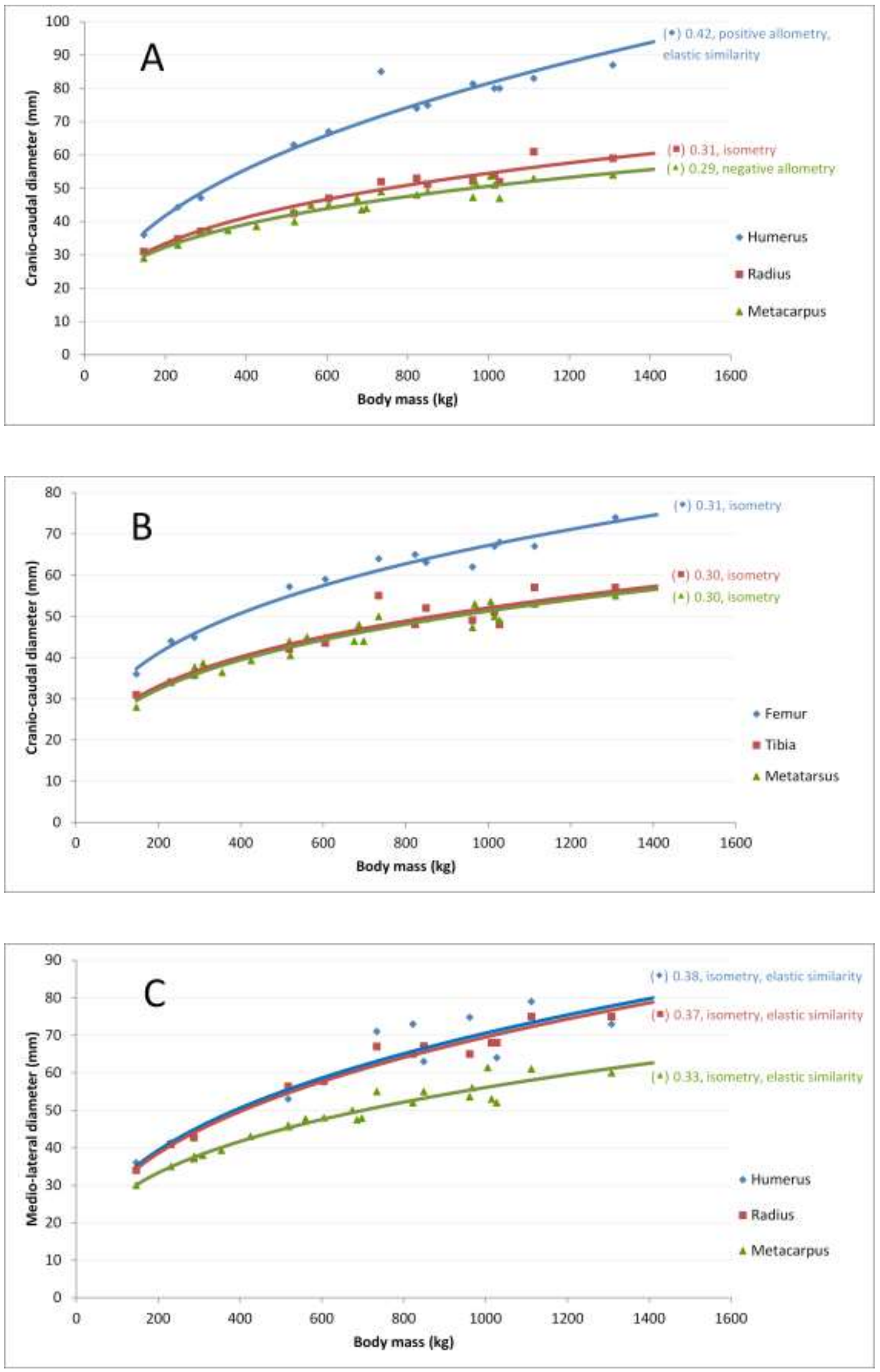


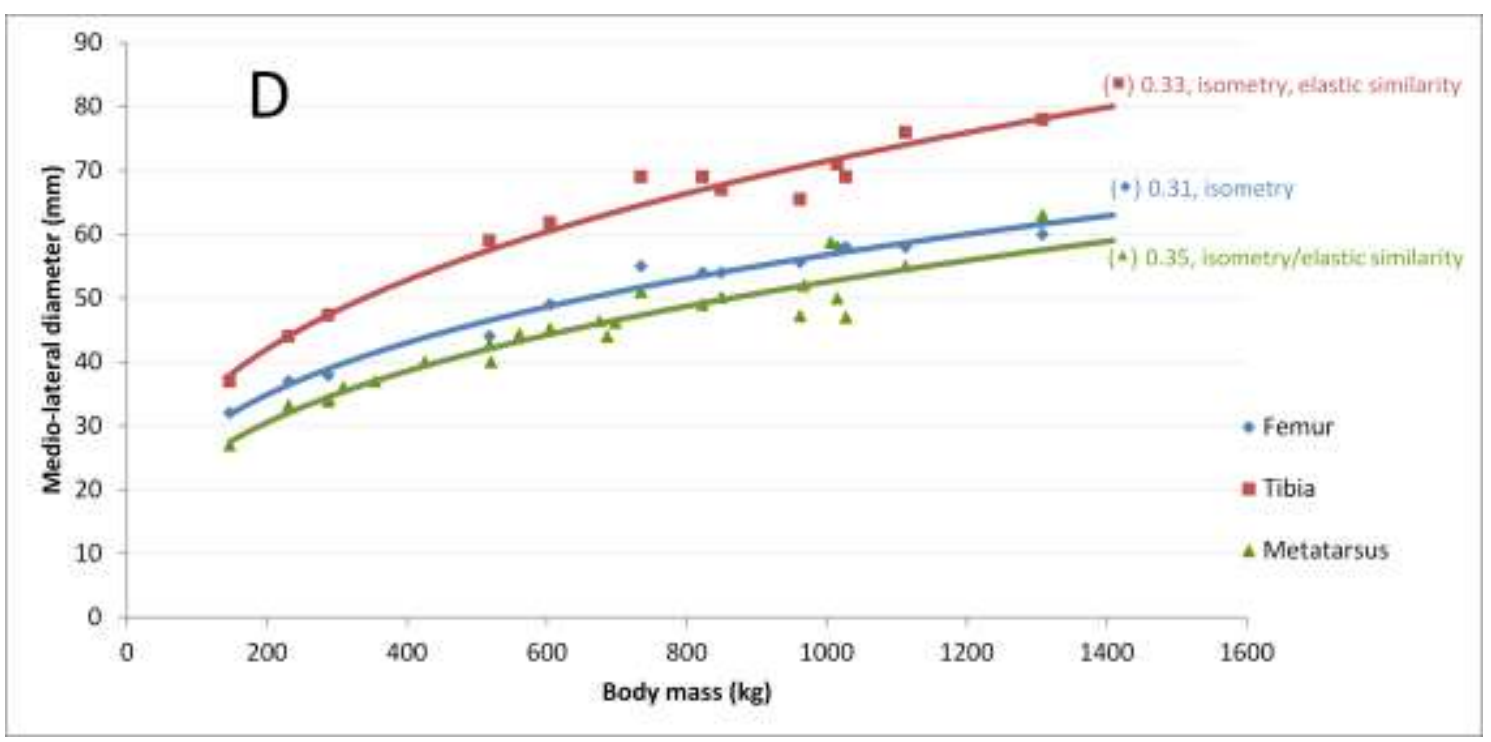

Fig. 3. Cranio caudal (A, B) and medio-lateral (C, D) diameters of the long bones of the post natal appendicular skeleton with regard to body mass. Note the positively allometric and elastically similar growth of the humerus in CC diameter. The only bones to grow with significant negative allometry were the metacarpals in CC diameter. None of the other bone diameters could be discerned from isometry with enough statistical certainty. The allometric exponent and its classification are indicated next to each curve.

The same general pattern was seen when individual bone diameters were evaluated.

The growth rate of fetal diameters with regard to body mass was not different to elastic similarity and thus greater than geometric similarity. In certain cases however (femur and tibia $\mathrm{CC}$ and $\mathrm{ML}$ ), the exponents were not significantly different from either geometric or elastic similarity due to wide confidence intervals.

In postnatal animals the humerus $\mathrm{CC}(0.42$, positive allometry) and metacarpus CC $\left(0.29\right.$, negative allometry) exponents were different from isometry $\left(p_{(H 0: b=0.333)}=0.002\right.$ and 0.006 respectively). The humerus $\mathrm{CC}$ was the only exponent similar to elastic similarity $\left(p_{(H 0: b=0.375)}=0.06\right)$. None of the $M L$ slopes were different from isometry. However it is important to consider that, apart from the femur $\operatorname{ML}\left(p_{(H 0: b=0.375)}<0.001\right)$, none of the ML slopes were different from elastic similarity either. This indicates that confidence intervals for ML exponents are too wide to detect significant differences 
from either isometry or negative allometry. The probably for elastic similarity is however greater than isometry in the humerus and radius $\mathrm{ML}$ diameter: $\mathrm{p}_{(\mathrm{H} 0: \mathrm{b}=0.375)}=$ 0.91 (humerus) and 0.78 (radius); $\mathrm{p}_{(\mathrm{HO}: \mathrm{b}=0.333)}=0.16$ (humerus) and 0.03 (radius). Increases in circumference followed the same general pattern as diameter. The difference between the mean fetal $(0.38 \pm 0.03)$ and postnatal $(0.32 \pm 0.04)$ exponents was significant $(p<0.01)$. Changes in postnatal circumference were positively allometric in the humerus (exponent $=0.39$ ), negatively allometric in the femur (exponent $=0.29$ ) and metapodials (both exponents $=0.30$ ), and isometric in the radius (exponent $=$ 0.33 ) and tibia (exponent $=0.31)$. Only the humerus increased in circumference according to elastic similarity.

In the postnatal forelimb absolute circumference decreased from proximal to distal bones. The circumference of the humerus increased more (2.7-fold) than that of the radius (2.4-fold) or metacarpus (2.2-fold) from birth to adult. In the hind limb the increase in tibial circumference was the greatest. As would be expected from the circumferential growth exponents, hind limb bone thicknesses stayed fairly constant relative to each other: the diameters increased from 2.1 (femur) to 2.2-fold (tibia and metatarsus) from neonate to adult.

Increase in diameters and circumference with bone length as covariate A one way ANOVA was conducted to test for differences in the mean fetal and postnatal diameter vs bone length slopes. We found a significant difference $\left(F_{(3,20)}=\right.$ 4.09, $p=0.02)$ amongst fetal CC (1.29 \pm 0.14$), M L(1.27 \pm 0.11)$, postnatal CC (1.05 $\pm 0.21)$ and $M L(1.13 \pm 0.08)$ slopes. Nevertheless, post hoc t-tests using the sequencial 
bonferonni technique could not show a difference between corresponding fetal and postnatal groups $\left(p_{(C C \text { fetal }}=\right.$ postnatal $)=0.04, p_{(M L \text { fetal }}=$ postnatal $)=0.03$. Similarly, when individual dimensions were compared across these age groups, only the radial diameters ( $\mathrm{CC}$ and $\mathrm{ML}$ ) and the metatarsus $\mathrm{CC}$ diameter could be shown as significantly different $\left(\right.$ radius $\mathrm{CC}_{\text {fetus slope }}=1.24$ compared with $\mathrm{CC}_{\text {postnatal slope }}=0.88, \mathrm{p}_{\text {(HO: fetus slope }}=$ postnatal slope $)=0.002 ;$ radius $\mathrm{ML}_{\text {fetus slope }}=1.35$ compared with $\mathrm{ML}_{\text {post-natal slope }}=1.06, \mathrm{p}_{\text {(HO: }}$ fetus slope $=$ postnatal slope) $=0.034) ;$ metatarsus $\mathrm{CC}_{\text {fetus slope }}=1.48$ compared with $\mathrm{CC}_{\text {postnatal slope }}=$ $\left.0.96, \mathrm{p}_{(\mathrm{HO} \text { : fetus slope }=\text { postnatal slope })}=0.004\right)$. This was because the small fetal sample sizes caused much wider confidence intervals for the exponents, decreasing the power to detect differences from post natal samples.

For the same reason many of the fetal exponents could not be distinguished from isometry despite being large. The humeral CC exponent was positively allometric (1.41) but its ML exponent was still isometric (1.18), similar to both femoral diameters $(C C=$ 1.11 and $M L=1.18)$. Radial exponents increased with significant positive allometry in both diameters $\left(\mathrm{CC}_{\text {fetus slope }}=1.24, \mathrm{ML}_{\text {fetus slope }}=1.35\right)$. Neither of the tibial diameters could be distinguished from isometry $\left(\mathrm{CC}_{\text {fetus slope }}=1.26, \mathrm{ML}_{\text {fetus slope }}=1.09\right)$. Similarly, the metacarpal exponents could not be shown different from isometry despite being large $\left(\mathrm{CC}_{\text {fetal slope }}=1.26, \mathrm{ML}_{\text {fetal slope }}=1.32\right)$, whereas the metatarsals could $\left(\mathrm{CC}_{\text {fetal slope }}=\right.$ $1.48, \mathrm{ML}_{\text {fetal slope }}=1.42$ ).

Figure 4 illustrates the relationship between bone diameter and bone length in postnatal giraffes during growth. During this phase both CC diameters of the humerus $\left(\mathrm{CC}_{\text {postnatal slope }}=1.37\right)$ and femur $\left(\mathrm{CC}_{\text {postnatal slope }}=1.23\right)$ increased with positive 

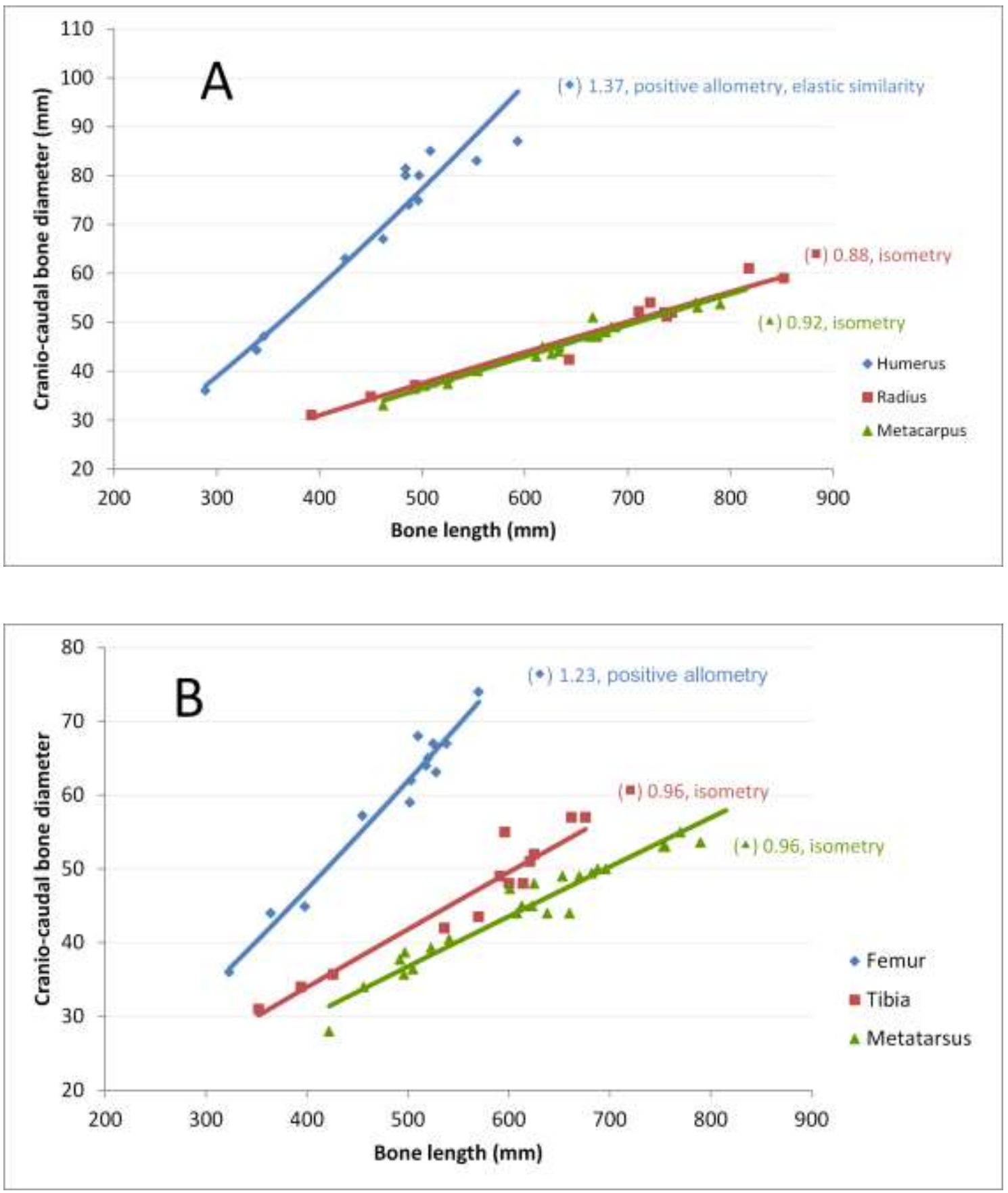

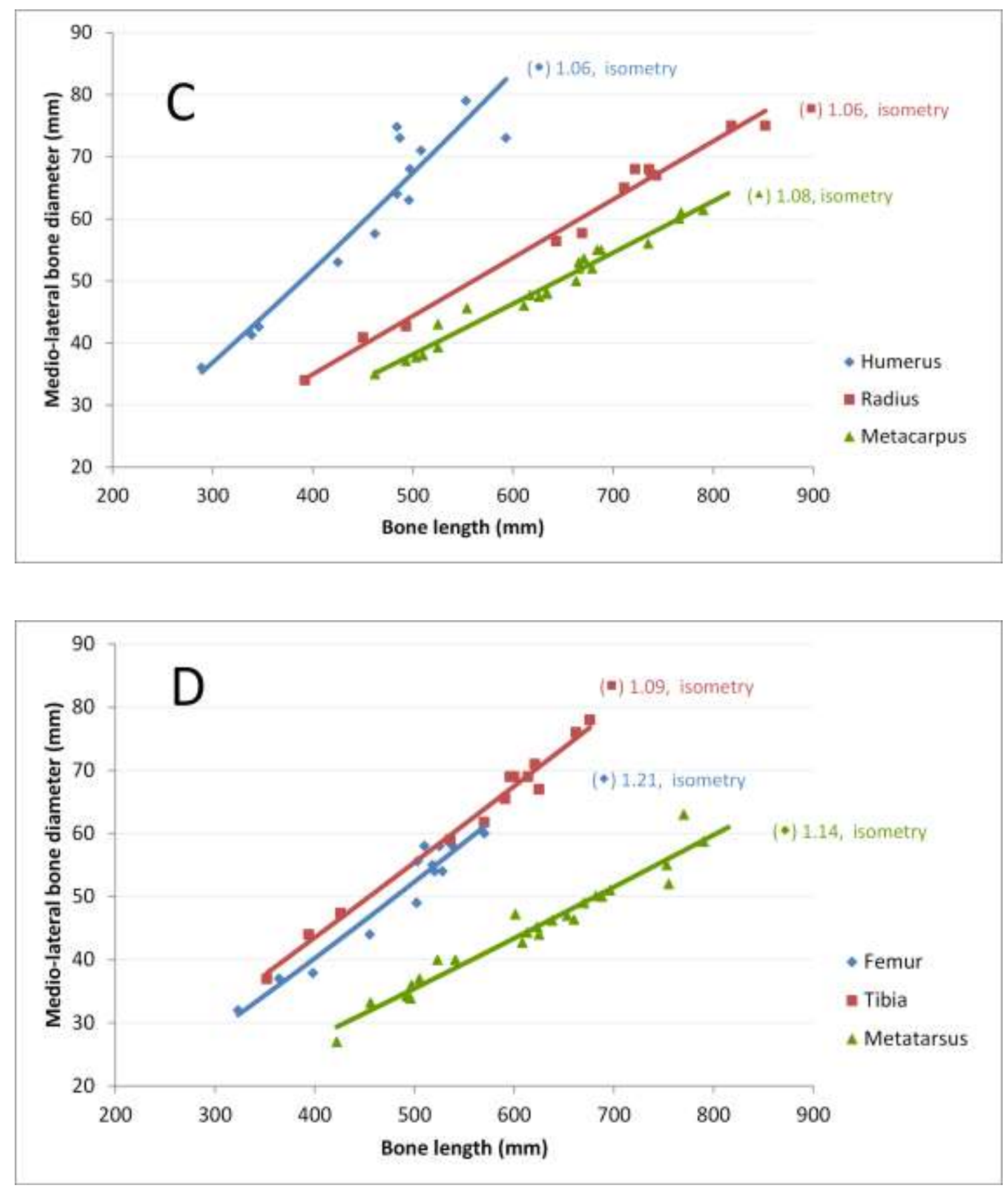

Fig. 4. Cranio-caudal (A,B) and medio-lateral (C,D) diameters versus length plots in post natal animals. Note the positive allometric scaling of the humerus and femur in both diameters. The allometric exponent and its classification are indicated next to each curve.

allometry relative to increases in bone length (for both bones $\mathrm{p}_{(\mathrm{HO}: \mathrm{b}=1.00)} \leq 0.002$ ). The cranio-caudal exponent of the humerus was not significantly different from elastic similarity (viz., 1.5), the only diameter to increase in this way out of all postnatal bones 
(for all other bones $\left.\mathrm{p}_{(\mathrm{HO}: \mathrm{b}=1.5)} \leq 0.003\right)$. Diameters of long bones below the elbow and knee did not grow significantly different from isometry (note that the sequential Bonferroni technique was applied to post hoc comparisons, with $k=4$, and therefore certain $p$-values $\leq 0.05$ were still considered non-significant.) In the bones below the elbow and knee the ML diameter exponents were significantly greater than the CC exponents $\left(p_{(H O}: C C=M L\right.$ slope $\left.) \leq 0.023\right)$, except in the tibia.

When considering increases in bone circumference with regard to increases in bone length, we could not detect significant differences between the mean fetal and postnatal slopes (mean exponent $=1.07$ for both). The diameters of the humerus (exponent $=1.27)$ and femur (exponent $=1.18)$ in postnatal giraffes increased positively allometric with regard to bone length $\left(p_{(H O: b=1.00)} \leq 0.006\right)$, while those in all the other bones increased isometrically (exponents range from 0.97 to 1.02 ).

In summary, fetal diameter and circumference vs. bone length slopes could not be shown to be significantly higher than postnatal slopes. Post-natal humeral and femoral diameters and circumferences increased relatively faster than length. Cranio-caudal diameters increased relatively slower than that of medio-lateral diameters in the bones below the humerus, to the extent that the distal front leg bones become relatively more slender in the cranio-caudal plane as the animal matures.

Comparing the bone length : circumference ratio gives a measure of how robust bones are. The mean ratio (from neonate to adult) for the humerus is 2.3 which is more robust than that of the femur (ratio $=2.8$, t-test, $p<0.001$ ). This could indicate that the humerus carries more weight than the femur. The opposite is true for the radius and 
tibia - the radius's mean ratio was 3.7 , significantly less robust $(p<0.001)$ than the mean tibia ratio (3.1). This shows that the tibia is probably exposed to higher stresses and strains than the radius especially in the CC direction. The mean metatarsal ratio (4.0) is slightly albeit significantly greater than the metacarpal ratio (3.9, $p=0.017)$. These ratios also illustrate that the metapodials are far more gracile than other limb bones.

Changes in cross sectional area (CSA) with body mass and bone length as covariates Relative to increases in body mass the mean fetal $(0.91 \pm 0.03)$ and postnatal $(0.66 \pm$ $0.07)$ exponents were significantly different $(p<0.01)$.

In postnatal animals none of the CSA vs body mass slopes were significantly different from isometry ( $p \geq 0.018$, using sequential bonferonni technique). Nevertheless, unlike the other bones $(p \leq 0.013)$, the humerus and radius CSA slopes were also not different to elastic similarity $\left(\mathrm{Bm}^{0.80}, \mathrm{p}_{(\mathrm{HO} \text { : slope }=0.75)}=0.36\right.$ and $\mathrm{Bm}^{0.68,} \mathrm{p}_{(\mathrm{HO} \text { : slope }=0.75)}=0.03$ respectively, sequential bonferonni technique). The radius CSA slope has a much higher probability $(p=0.81)$ of being similar to isometry however, and its nonsignificant difference to the elastic similarity exponent was probably brought about by loss of power by the Bonferroni technique (Fig $5 \mathrm{~A}$ and $\mathrm{B}$ ). The mean fetal CSA vs. bone length slope was significantly higher (mean $=2.52 \pm 0.22$, isometry $=2.00$ ) from the postnatal mean $(2.17 \pm 0.28 ; p<0.05)$. During postnatal growth only the humerus and femur could be shown to have a CSA growth pattern that was significantly and positively allometric relative to increases in length ( $p \leq 0.004$; Fig 5C and 5D). 

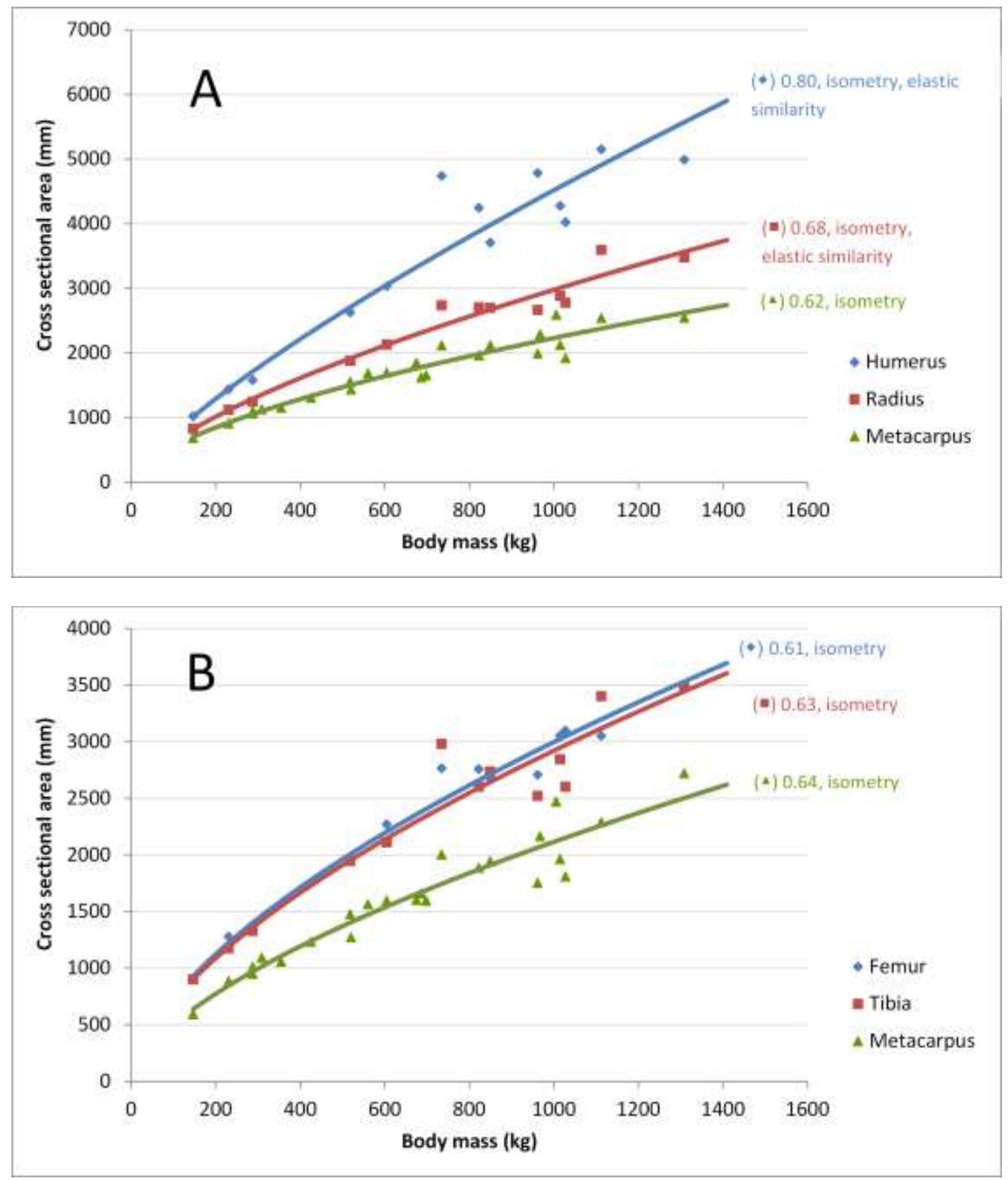

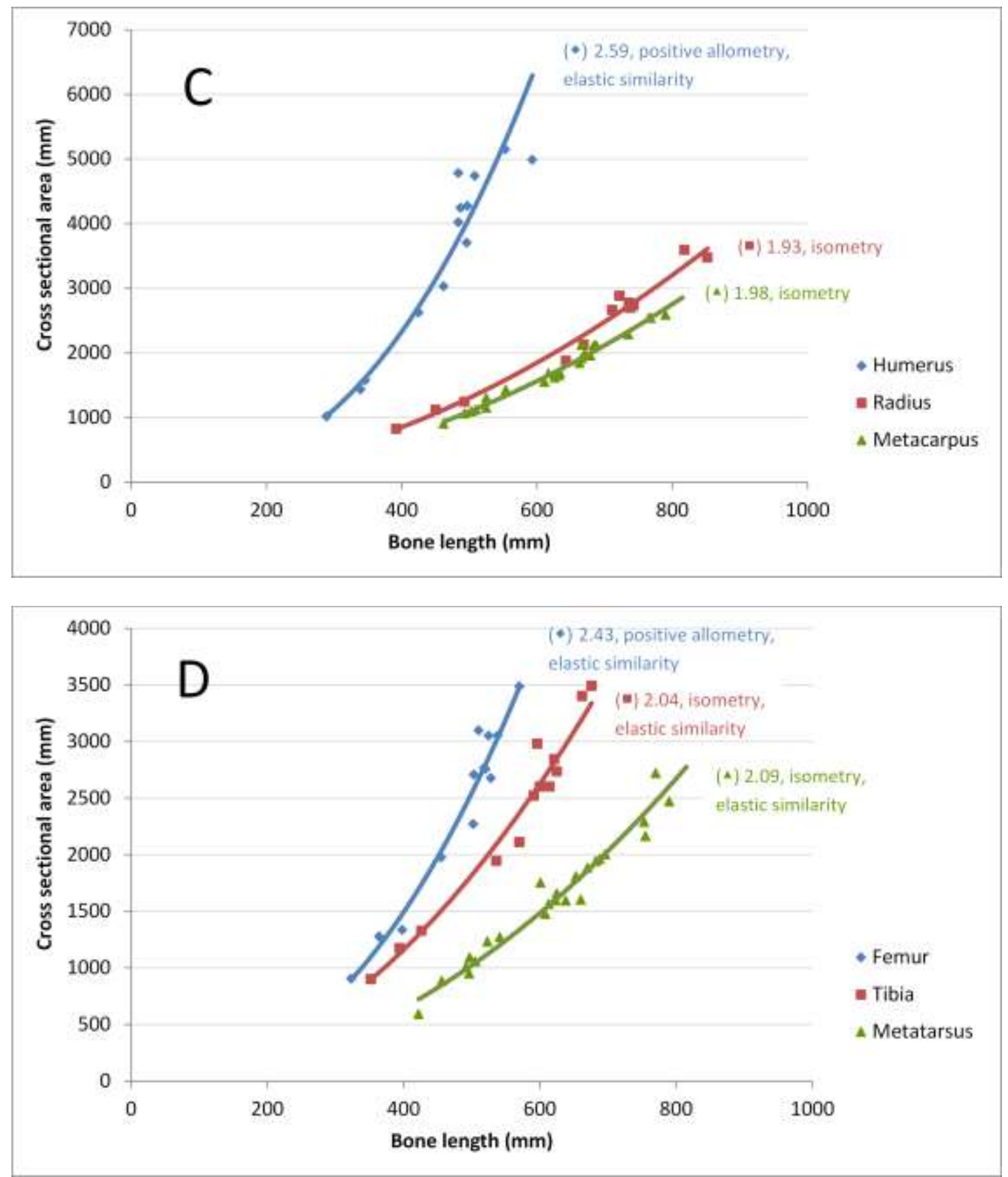

Fig. 5. Growth in cross sectional area (CSA) with regard to body mass (A,B) and bone length (C,D). When compared to body mass, none of the exponents could be shown different from isometry, despite some (humerus and radius) also being equal to elastic similarity. When compared to bone length, however, both the humerus and femur increase with positive allometry. The allometric exponent and its classification are indicated next to each curve. 


\section{Discussion}

Pre- and postnatal growth differences

This study has illustrated that, as expected, there are significant differences between pre- and postnatal limb bone development in giraffes. Although the fetal skeleton is shaped through epigenetic as well as genetic factors (Carter et al., 1996), it nevertheless does not have to support weight. The postnatal skeleton on the other hand has to adapt to stresses and strains imposed by an increasing body mass and movement, and shapes itself to incorporate the necessary safety factors against failure.

The transition from a life in utero to that outside of it will therefore only be successful if certain 'day one' skeletal competencies have been established before birth. It follows that these competencies are almost wholly genetically dependent. We have demonstrated that in the prenatal skeleton, where the effects of gravity are countered by the buoyancy inside the uterus, growth proceeds in length and width positively allometric with regard to body mass. Postnatally however, this positive allometric trend is either not possible (because of biomechanical constraints) or necessary for survival.

\section{Sexual dimorphism}

We did not expect to find sexual dimorphism between equivalent body mass giraffes, and we did not find any. Our expectation was based on the lack of dimorphism in giraffe neck length and cervical vertebrae growth patterns (Mitchell et al., 2009, 2013; 
van Sittert et al., 2010). The results we report here further confirm that sexual selection has not played a major (if any) role in the evolution of tallness in giraffes.

Length vs. body mass

Length growth relative to body mass does not give an indication of the slenderness of the bone, but does highlight whether the limb bones lengthen faster than body size or not. Although limb bones lengthened with positive allometry in utero, we did not foresee that none of the giraffe limb bones would grow with positive allometry after birth, given the remarkable length of the legs. In fact, giraffes do not seem to have uniquely high postnatal limb lengthening exponents at all (Fig 6A). However, this finding remains preliminary until more studies describing limb lengthening with regard to body mass are published, especially in artiodactyls. 

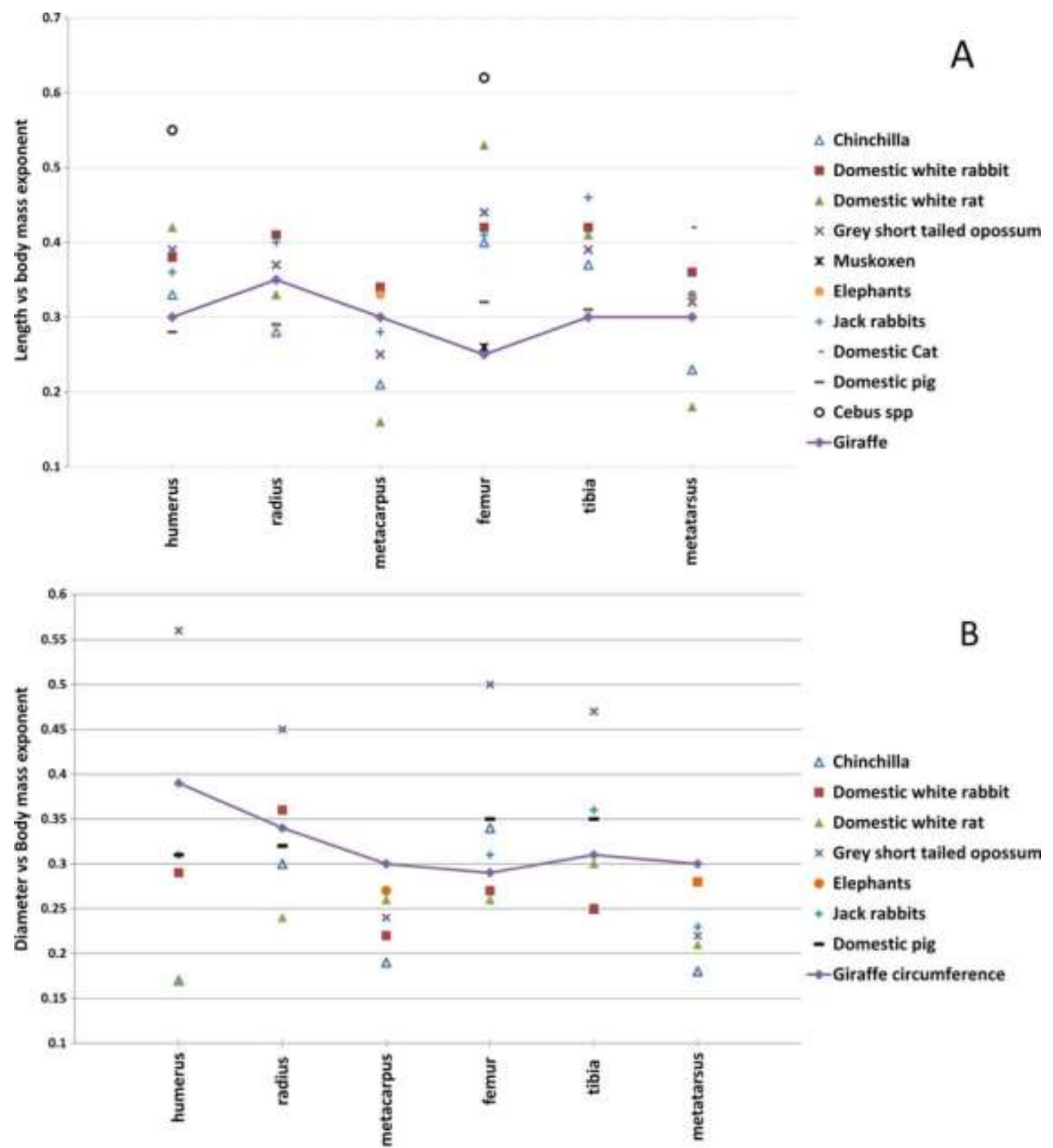

Fig. 6 (A) Length vs. Body mass ontogenetic exponents of previously described species. Note that giraffe exponents are within the range of previously described exponents, except in the femur and tibia where it is, surprisingly slightly lower than previously described exponents. (B) Diameter versus body mass exponents of previously described species. Because two giraffe diameters were taken in this study, the circumference exponent was chosen to represent average diameter growth. Giraffes do seem to have higher metapodial exponents, but note that there are no artiodactyls in the metapodial samples. Furthermore, data on artiodactyls comparable to this study are still very scant, and conclusion should be drawn with caution. Data from Carrier (1983); Heinrich et al. (1999); Liu et al. (1999); Lammers and German (2002); Miller et al. (2008); and Young et al. (2010). The giraffe exponents (this study) are connected with a line for emphasis. 
The postnatal negatively allometric/isometric lengthening of limb bones contrasts with the positively allometric lengthening of the C2-C7 cervical vertebrae (mean cervical scaling exponent $=0.41 \pm 0.01)$, and is also less than the more isometric T2-T14 and L1 to $L 5$ vertebrae (both $0.34 \pm 0.01$ ) (van Sittert et al., 2010). The fastest growth in leg length occurred in the first year of life with the final limb length of mature animals being approximately twice their length at birth compared to a three-fold increase in neck length (Mitchell et al., 2009). Giraffes thus have relatively longer limbs and shorter necks per unit body mass as juveniles, and the remarkable length of limb bones per body mass seems to be established in utero already. Note that it is not unusual for a precocial species to have relatively longer legs as juveniles, where the animal needs to be mobile within hours after birth, and needs to take advantage of longer legs to increase speed and stride length (Carrier, 1983; Heinrich et al., 1999; Grossi and Canals, 2010). Furthermore, giraffe ontogenetic limb proportions do not seem to differ much from proportions known in other artiodactyls. For example, giraffe front limb proportions are in agreement with cervid proportions at birth, while hind limb proportions are only slightly different: giraffes have higher femoral (30\%, cervid range 28-29\%), lower tibial (32\%, cervid range 36-38\%) and higher metatarsal (38\%, cervid range 33-36\%) proportions (Van der Geer et al., 2006). Adult giraffe limb bone proportions similarly fit within described cervid ranges in the front limb but were lower in the femur and tibia and higher in the metatarsus. Interestingly, cervid radii start out shorter but end up longer than the metacarpus, similar to giraffes.

The sum of the lengths of the three main bones of the front legs of giraffes is slightly longer than that of the hind legs (from about $40 \mathrm{~mm}$ in a neonate to $140 \mathrm{~mm}$ in an 
adult $1300 \mathrm{~kg}$ giraffe; Table 3). This finding supports an observation by Colbert in 1938 that, in contrast to other ruminants, the front legs of giraffe are longer than the back legs and thereby contribute to the appearance of a sloping back. It should be clarified, however, that, a) the sum of long bone lengths is not the same as leg length as the manus and pes is excluded, and b) contrary to what Colbert noted, neither the total front leg nor any of its constituent long bones lengthen significantly more than those of the hind legs. Rather, the radius starts out longer than the tibia at birth, with their relative growth rates staying fairly similar during postnatal ontogeny. We were also surprised to find that the longest bones in the giraffe limb were the radius and tibia, and that the appearance of longer metapodials is probably an optical illusion caused by their remarkable slenderness and verticality, and the contrast with thicker limb diameters at the region of the zeugopodials.

Increase in diameter and circumference with regard to body mass

Giraffe long bones all increase in diameter and circumference in utero at a rate faster than increases in body mass. Conversely, postnatal diameters increase iso- or negatively allometric to body mass, except the humeral $\mathrm{CC}\left(\mathrm{Bm}^{0.42}\right)$ and radial $\mathrm{ML}$ $\left(\mathrm{Bm}^{0.37}\right)$ diameters. Note however that although the humeral ML diameter could not be shown significantly different from isometry, its growth exponent is still high $\left(\mathrm{Bm}^{0.38}\right.$, $\mathrm{p}_{(\mathrm{HO}: \mathrm{b}=0.33)}=0.16$ and $\left.\mathrm{p}_{(\mathrm{HO}: \mathrm{b}=0.38)}=0.91\right)$, and significantly positive growth allometry may be hidden behind large confidence intervals. Therefore, it is possible that medio-lateral diameters from both humerus and radius grow with positive allometry and may indicate buttressing against a commonly encountered strain in this plane. 
Alternatively, if indeed only the humeral cranio-caudal and radial medio-lateral diameters increase with positive allometry, this may indicate buttressing against a commonly encountered strain shared during movement or during stances such as drinking, when these two diameters may share a common plane. Nevertheless, the fact that the giraffe humeral and radial ML diameters become more robust relative to body mass differs from the growth of the other long bones, and is almost certainly also related to the positively allometric increase in neck mass during growth (Mitchell et al., $2009,2013)$. Further study on giraffe limb bone posture and positioning will be needed before conclusions can be drawn.

It may seem superfluous to report both diameter and circumferential measurements. We believe however that bone circumference can be regarded as a summary of the two diameters and helps clarify patterns seen. For example, in postnatal giraffes only the humerus had a positive allometric change in circumference with regard to body mass, and thereby supports our supposition that this bone may become increasingly robust relative to body mass in both diameters. The positive allometry of radial $\mathrm{ML}$ diameter are offset by the lower isometric CC increase resulting in an overall isometric increase in radial circumference. On the other hand femur and metapodial circumferential growth does not keep up with increases in body mass. A second reason for including both circumferential and diameter data is to facilitate comparison with past and future studies, where often only one or the other is reported. Note as an example that metapodial circumferences, although increasing with negative allometry to body mass, still have higher exponents than other species previously reported (Fig 5B). 
It seems curious that limb diameters and circumferences do not increase at a faster rate than body mass to compensate for the larger loads upon it, especially in the direction of limb movement viz. CC diameter. This phenomenon is however well described. Younger animals have 'overbuilt' bones to compensate for reduced bone stiffness and locomotor ability, causing long bones to become more gracile in ontogeny. The relatively faster increase in ML diameters compared to CC diameters in giraffes may also be related to safety factors required for when this animal drinks water and the front legs are splayed apart, putting more stress and strain on the medio-lateral aspects of the bones. Other possible correlates to this effect such as mating behavior, neck length and general artiodactyl traits need to be borne in mind and further data and studies are needed to explain this observation.

Diameter and circumference vs. length

In this type of analysis, isometry denotes a bone which increases in length and diameter at the same rate.

Individual fetal and postnatal slopes could not be distinguished because of wide confidence intervals for fetal exponents. Whereas the stylopodial (humerus and femur) bones grew robust in both directions, the trend for zeugopodial and metapodial bones was to grow more robust in medio-lateral direction than in cranio-caudal direction. Note that the femur becomes more robust with regard to its own length, but not with regard to body mass. We propose that this is because a large part of body mass is carried in the neck and therefore front limb. Unfortunately, we could not find comparative ontogenetic data in the literature, and our proposition cannot be tested 
until further data becomes available. Nevertheless, this finding stresses the importance of interpreting changes in bone cross sectional area in terms of bone length as well as with regard to body mass.

We found no long bone circumference to grow according to McMahon's (1975) elastic similarity model. Indeed, Kilbourne and Makovicky (2012) showed elastic similarity (Length $(\mathrm{L}) \propto$ Circumference $(\mathrm{C})^{0.67}$ or $\left.\mathrm{C} \propto \mathrm{L}^{1.5}\right)$ to be the exception rather than the rule in ontogeny of mammals. They also demonstrated that cetartiodactyl limb bones generally become more robust during ontogeny (i.e. $L \propto C^{<1.00}$ ). A notable exception to this pattern was the okapi (Okapia johnstoni), in which the bone length to circumference exponents was $>1.00-$ i.e. bones became increasingly slender during growth. As okapi represent the ancestral morphology of giraffe (Mitchell and Skinner, 2003), and as giraffes and okapis have slender legs compared to other ungulates (McMahon, 1975; Scott, 1990; Kilbourne and Makovicky, 2012), we would have expected that the giraffe would grow more gracile legs throughout ontogeny as well. Contrarily, we found the giraffe is born with such slender legs that they are not capable of decreasing in relative circumference any further. This appears to us to be a classic example of ontogeny revealing key milestones in phylogeny as proposed by Pincher (1949). Pincher suggested that the evolution of neck elongation in giraffes was a secondary response to leg elongation, in order for the animal to reach the ground to drink. However, we do not believe neck elongation was a response to aid drinking in giraffes as the neck length grows disproportionately faster than leg length (Mitchell et al., 2009; van Sittert et al., 2010). Leg elongation on the other hand may have been accompanied by increases in body mass which will have required more browsing strata 
from which to feed (Jarman-Bell Principle;du Toit, 2005), in turn necessitating disproportionate neck length increase. This idea is supported by studies that showed that giraffes utilize various feeding strata in trees (Cameron and du Toit, 2007) and even graze (Seeber et al., 2012). The neck therefore is not only advantageous during a dearth as Darwin proposed in 1888, but essential throughout all seasons.

\section{Cross sectional area (CSA)}

Although it has been shown that long bone periosteal contours correlate highly with cross sectional properties in adult human populations, this does not necessarily hold for individuals, subadults nor for other species (Sparacello and Pearson, 2010). In addition, cortical thickness has been shown to be significantly greater in giraffes compared to buffaloes (van Schalkwyk et al., 2004). In order to see if the medullary cavity could have an influence on our findings, we subtracted an estimate of endosteal area from periosteal area, using cortical thickness measurements. However, our findings remained similar even when estimating cross sectional area without a medullary cavity. Arguably, this is a very rough estimate and more accurate measures of CSA as well as second moment of area are needed in future.

Goat and elephant CSA's become more gracile with body mass during growth: both scaling as $\mathrm{Bm}^{0.53}$ (Main and Biewener, 2004; Miller et al., 2008). Because this causes increased strain and reduced resistance to bending, it was proposed that younger animals have overbuild bones to compensate for less stiff bones. Giraffe limb bones do not grow more gracile during growth which means either that giraffe calves does not 
have overbuild bones or that the long neck prohibits bones from becoming more gracile.

Practical application of giraffe allometric equations

Previous authors proposed the giraffe metapodials to be the seat of limb propulsion and elongation (Thompson, 1917; Colbert, 1938; McMahon, 1975). In proficient runners it has been shown that the elongated distal elements are more energy efficient and increase stride length (Carrier, 1983; Christiansen, 2002; Lammers and German, 2002; Young et al., 2014). Our data show however that the metapodials of giraffes do not elongate more than other limb bones over their lifetime. The lengths of the radius and tibia increase ca. 2.3 fold between birth and maturity while the length of the metapodials increases only 1.95 fold. Thus, although greatly elongated, the specialization of the most distal limb segments in giraffes does not seem to be an adaptation to increase locomotor efficacy as one of the principle functions (Pincher, 1949).

\section{Conclusion}

This study is set apart by the quality of its sampling base; a broad range of bone parameters were measured, body mass was measured (not inferred) and a broad population of wild (not zoo) giraffes was available. We found that the giraffe appendicular skeleton does not elongate in the dramatic way the neck does. Limbs at birth, after lengthening with positive allometry in utero, are already elongated and slender in shape and a further increase in the gracility of the bones is probably not possible. The humerus is the only bone that becomes increasingly robust with regard 
to body mass and bone length, suggesting functional adaptation to increasingly high loads and/or bending moments, which may be caused by the neck mass which increases with positive allometry and the need for giraffe forelimbs to bend at the carpus and splay during drinking. It may also be related to the orientation of the humerus to the ground, but this needs to be substantiated by further study. Indeed, a broader range of species (in particular artiodactyls) and their body mass through ontogeny needs to be sampled before definitive conclusions can be reached. Further clues regarding the functionally of the giraffe's slender bones will also lie in the cross sectional distribution of bone around the centroid, whole bone geometry and bone curvature.

\section{Acknowledgments}

Funds were provided through the Don Craib Trust, University of Wyoming, Maberly Memorial Scholarship and JD Skinner's Personal Research Fund. We thank Bubye Valley Conservancy for their hospitality and willingness to make the specimens and labor available to us. Further field support was provided by Carl-Heinz Moeller, Kenneth Manyangadze, Mark Brewer, Andrew Henning, Lauren Leathem, Struan Muirhead, David Roberts, Nicky Buys and Blake Wilhelmi. Thanks to Thijs Mandersloot for explaining and suggesting some of the biomechanical concepts involved in this study.

\section{References}

Alexander R, Jayes AS, Maloiy GMO, Wathuta EM. 1979. Allometry of the limb bones of mammals from shrews (Sorex) to elephant (Loxodonta). J Zool 189:305-314. 
Biewener AA. 1983. Allometry of quadrupedal locomotion: the scaling of duty factor, bone curvature and limb orientation to body size. J Exp Biol 105:147-171.

Cameron ET, du Toit JT. 2007. Winning by a Neck: Tall Giraffes Avoid Competing with Shorter Browsers. Am Nat 169:130-135.

Carrier DR. 1983. Postnatal ontogeny of the musculo-skeletal system in the Blacktailed jack rabbit (Lepus californicus). J Zool Lond 201:27-55.

Carter DR, Van Der Meulen MC, Beaupré GS. 1996. Mechanical factors in bone growth and development. Bone 18:5S - 10S.

Christiansen PER. 2002. Locomotion in terrestrial mammals: the influence of body mass, limb length and bone proportions on speed. Zool J Linn Soc 136:685-714.

Colbert EH. 1938. The relationships of the okapi. J Mammology 19:47-64.

Currey JD. 2002. Bones: Structure and Mechanics. Princeton University Press. 464 p.

Darwin CR. 1888. The origin of species: By means of natural selection, the preservation of favoured races in the struggle for life. In: 6th ed London: John Murray. p. 177.

Du Toit JT. 2005. Sex differences in the foraging ecology of large mammalian herbivores. In: Ruckstuhl K, Neuhaus $\mathrm{P}$, editors. Sexual Segregation in Vertebrates Cambridge: Cambridge University Press. p. 35-52.

Economos AC. 1983. Elastic and/or geometric similarity in mammalian design? J Theor Biol 103:167-172.

Falster DS, Warton DI, Wright IJ. 2006. SMATR: Standardised Major Axis and Routines Ver. 2.

Galilei G. 1914. Dialogues concerning two new sciences. New York Macmillan. 346 p. 
Garcia GJ, da Silva JKL. 2006. Interspecific allometry of bone dimensions: A review of the theoretical models. Phys Life Rev 3:188-209.

Grossi B, Canals M. 2010. Comparison of the morphology of the limbs of juvenile and adult horses (Equus caballus) and their implications on the locomotor biomechanics. J Exp Zool Part Ecol Genet Physiol 313:292-300.

Hall-Martin AJ. 1975. Studies on the biology and productivity of the Giraffe Giraffa camelopardalis [DSc.]. Pretoria: University of Pretoria.

Heinrich RE, Ruff CB, Adamczewski JZ. 1999. Ontogenetic changes in mineralization and bone geometry in the femur of muskoxen (Ovibos moschatus). J Zool 247:215223.

Huxley JS. 1932. Problems of relative growth. New York: The dial press. xix +276 p.

Kilbourne BM, Makovicky PJ. 2012. Postnatal long bone growth in terrestrial placental mammals: Allometry, life history, and organismal traits. J Morphol 273:11111126.

Kokshenev VB. 2003. Observation of mammalian similarity through allometric scaling laws. Phys Stat Mech Its Appl 322:491-505.

Lammers AR, German RZ. 2002. Ontogenetic allometry in the locomotor skeleton of specialized half-bounding mammals. J Zool 258:485-495.

Main RP, Biewener AA. 2004. Ontogenetic patterns of limb loading, in vivo bone strains and growth in the goat radius. J Exp Zool 207:2577-2588.

McMahon TA. 1973. Size and shape in biology. Science 179:1201-1204.

McMahon TA. 1975. Allometry and Biomechanics: Limb Bones in Adult Ungulates. Am Nat 109:547-563. 
Miller CE, Basu C, Fritsch G, Hildebrandt T, Hutchinson JR. 2008. Ontogenetic scaling of foot musculoskeletal anatomy in elephants. J R Soc Interface 5:465-475.

Mitchell G, Roberts D, van Sittert S, Skinner JD. 2013. Growth patterns and masses of the heads and necks of male and female giraffes. J Zool 290:49-57.

Mitchell G, van Sittert SJ, Skinner JD. 2009. Sexual selection is not the origin of long necks in giraffes. J Zool Lond 278:281-286.

Pincher C. 1949. Evolution of the giraffe. Nature 164:29-30.

Rice WR. 1989. Analyzing tables of statistical tests. Evolution 43:223-225.

Scott K. 1990. Postcranial dimensions of ungulates as predictors of body mass. In: Damuth J, MacFadden BJ, editors. Body size in mammalian paleobiology Cambridge University Press.

Seeber PA, Ndlovu HT, Duncan P, Ganswindt A. 2012. Grazing behaviour of the giraffe in Hwange National Park, Zimbabwe. Afr J Ecol 50:247-250.

Selker F, Carter DR. 1989. Scaling of long bone fracture strength with animal mass. J Biomech 22:1175-1183.

Skinner JD, Hall-Martin AJ. 1975. A note on foetal growth and development of the giraffe Giraffa camelopardalis giraffa. J Zool Lond 177:73-79.

Sparacello VS, Pearson OM. 2010. The importance of accounting for the area of the medullary cavity in cross-sectional geometry: A test based on the femoral midshaft. Am J Phys Anthropol 143:612-624.

Thompson DW. 1917. On growth and form. Cambridge [Eng.] University press. 824 p. 
Van der Geer A, Dermitzakis M, De Vos J. 2006. Relative growth of the metapodals in a juvenile island deer: Candiacervus (Mammalia, Cervidae) from the Pleistocene of Crete. Hell J Geosci 41:119-125.

Van Schalkwyk OL, Skinner JD, Mitchell G. 2004. A comparison of the bone density and morphology of giraffe (Giraffa camelopardalis) and buffalo (Syncerus caffer) skeletons. J Zool 264:307-315.

Van Sittert SJ, Skinner JD, Mitchell G. 2010. From fetus to adult - an allometric analysis of the giraffe vertebral column. J Exp Zoolog B Mol Dev Evol 314B:469-479.

Warton DI, Wright IJ, Falster DS, Westoby M. 2006. Bivariate line-fitting methods for allometry. Biol Rev Camb Philos Soc 81:259-291.

Young JW, Danczak R, Russo GA, Fellmann CD. 2014. Limb bone morphology, bone strength, and cursoriality in lagomorphs. J Anat 225:403-418. 